Çukurova Üniversitesi Mühendislik Mimarlık Fakültesi Dergisi, 31(1), 363-370 ss., Haziran 2016

Çukurova University Journal of the Faculty of Engineering and Architecture, 31(1), pp.363-370, June 2016

\title{
İnşaat Mühendisleri Özelinde Meslek Etiğinin Algılanma ve Uygulanma Düzeyi
}

\author{
Olcay GENÇ ${ }^{* 1}$, Ercan ERDIŞ̧ ${ }^{1}$, Hilmi COŞKUN ${ }^{1}$ \\ ${ }^{1}$ İskenderun Teknik Üniversitesi, İnşaat Fakültesi, İnşaat Mühendisliği Bölümü, İskenderun, \\ Hatay
}

Geliş tarihi: 01.02.2016 Kabul tarihi: 11.05.2016

\section{Özet}

Etik kelimesi Yunanca kökenli olup töre bilimi, ahlak bilimi, ahlaki, ahlakla ilgili gibi ifadelerle tanımlanmaktadır. Çalışma hayatındaki davranışları yönlendiren mesleki etik ise, etik prensipler ve standartların toplamı şeklinde ifade edilebilir. Bu çalışmanın amacı ise, Türk inşaat sektöründe çalışan inşaat mühendislerinin etik ve mesleki etik konusundaki yaklaşımlarını anlamak, bu kişilerin meslek hayatlarında etik olmayan bir durum karşısında verdikleri tepkiyi ölçmek, sektörde en çok hangi etik dışı davranışların sergilendiğini tespit etmek, bu tip davranışlarda bulunan kişilere nasıl ve ne şekilde yaptırımların uygulanabileceğini belirlemek ve etik olmayan davranışlarda bulunulmaması için olası çözüm önerilerini saptamaktır. Bunun için web tabanlı olarak hazırlanan bir anket, meslek odaları vasıtasıyla Türkiye'nin çeşitli ilerinde, kamu ve özel sektörde çalışan inşaat mühendislerine ulaştırılmıştır. Çalışma sonucunda; inşaat mühendislerinin etik dışı davranışlarda bulunmaması için, bu konudaki meslek etiği ilke ve kodları ile yasal mevzuatın bir an önce, tüm paydaşların önerileri doğrultusunda oluşturulmasının gerekliliği vurgulanmış, işverenlerin ve çalışanların meslek etiği konusunda duyarlılıklarını artıracak eğitimlerin verilmesinin önemine değinilmiş ve bu konuda ayrıca iç ve dış denetimlerin yapılmasının önemli olduğu belirtilmiştir.

Anahtar Kelimeler: Etik, Mesleki etik, Mühendislik etiği

\section{The Level of Perception and Implementation of Professional Ethics in Civil Engineering Perspective}

\begin{abstract}
Ethics that is a Greek origin word is described as related to morals, moral, and morality. The sum of the guiding ethical principles and standards of behavior in working life is called professional ethics. The main purpose of this study is to describe the ethical perception of civil engineers in Turkey. In this framework, the civil engineers' responses against unethical situations in their working environment, which unethical behavior is most exhibited by the technical staff working in the construction sector, how and which sanctions can be applied to those found in unethical behavior, and the possible solutions for not showing

\footnotetext{
* Yazışmaların yapılacağı yazar: Olcay GENÇ, İskenderun Teknik Üniversitesi, Inşaat Fakültesi, İnşaat
} Mühendisliği Bölümü, İskenderun, genc_olcay@hotmail.com
\end{abstract}


unethical behaviors are tried to be determined. A web-based questionnaire prepared for this purpose and the questionnaire was delivered to civil engineers who work in Turkish public and private sectors through chambers of civil engineering. In conclusion; it is stressed that the principles and codes of professional ethics with a needed state of the legislation should be established at once with the participation of all stakeholders to discourage civil engineers from engaging in unethical behaviors. Also it is mentioned that providing education to increase the awareness about professional ethics to employers and workers is important. Furthermore, it is emphasized that the internal and external audits should be conducted on this topic.

Keywords: Ethics, Occupational ethics, Engineering ethics

\section{GíRiș}

Etik terimi Yunanca karakter, töre, kültür anlamlarına gelen ethos kelimesinden gelmiş olup, töre bilimi, ahlak bilimi, ahlaki, ahlakla ilgili şeklinde tanımlanmaktadır.

Ülkemizde genellikle ahlak ve etik sözcükleri eş anlamlı olarak bilinmekte ve kullanılmaktadır. Etik; anlamı kişilere ve toplumlara göre değișen, insanın kendine ve çevresindeki diğer insanlara karşı iyi davranması için, kendini uymaya zorunlu hissettiği manevi görevler ve bunlara ilişkin kurallar bütünü iken, ahlak ise; belirli bir dönemde yaşamış toplulukların benimsemiş oldukları, bireylerin birbirleriyle ilişkilerini düzenleyen kurallar bütünüdür [1]. Ahlak, yaşadığımız topluma göre değişen ve genellikle çoğunluk tarafından doğru kabul edilen değerlerin toplamıdır. Doğru olduğu hissedilen kavram ve tutumlar ahlaka uygun, yanlış olduğu hissedilenler ise ahlaka aykırı olarak kabul edilir. Bu durum toplumdan topluma farklılık gösterebilmektedir. Özetle belirtmek gerekirse; etik, doğru ve yanlış davranış teorisi; ahlak ise onun pratiğidir. İlkeler söz konusu olduğunda etik kavramı, davranış söz konusu olduğunda ise ahlak kavramı kullanılır $[2,3]$.

Toplumsal yaşam içerisinde; bireylerin ayrı ayrı veya topluluklar halinde, diğer bireyler veya topluluklara karşı uyması gereken birtakım ahlaki kurallar vardır. Bu kurallar genel olarak; toplumun bütün üyelerine saygılı olmak , farklı kültürlere ve düşüncelere karşı hoşgörülü olmak, eşitlik, kaynakların adil olarak dağıtılması vb. şeklinde sıralanabilir. Ortak etik değerler ise; doğruluk, dürüstlük, güvenilir olma, sadakat, adalet, vatandaşlık sorumluluğuna sahip olma vb. şeklinde siralanabilir.

Bu çalışmanın amacı, kamu ve özel sektörde çalışan inşaat mühendislerinin etik ve mesleki etik algısını anlamak, bu kişilerin iş hayatlarında etik olmayan bir durum karşısında verdikleri tepkiyi ölçmek ve inşaat sektöründe çalışan teknik elemanların bilerek veya bilmeyerek en çok hangi etik dışı davranışları sergilediklerini belirleyerek, etik dişı davranışlarda bulunanlara nasıl ve ne şekilde bir yaptırımın uygulanabileceğini tespit etmek ve etik dışı davranışlarda bulunulmaması için olası çözüm önerilerini saptamaktır.

\section{MESLEK ETİĞİ}

Ahlak öncelikle toplumların temel taşı olan aileden öğrenilir. Aile içerisindeki ahlaki davranış biçimleri ile teorik ahlak öğretisinin uyumlu olması gerekmektedir. Aksi takdirde bireyin ahlaki gelişimi bundan olumsuz yönde etkilenebilir [3]. $\mathrm{Bu}$ da kişinin özel yaşamında ve çalışma hayatında ahlaki davranış sergilemesini engeller veya belirlenmiş etik ilkelere uyumunu zorlaştırır.

Etik yapısal ve içerik olarak;

- Genel Etik

- Meslek Etiği

- Görev Etiği

olmak üzere üç aşamada incelenebilir [1]. Çalışma hayatındaki davranışları yönlendiren, onlara rehberlik eden etik prensipler ve standartların 
toplamı mesleki etik olarak adlandırılır. Bu prensip ve standartlar temel olarak belirli bir meslek grubuna/üyelerine emreden, onları belli kurallara göre davranmaya zorlayan, kişisel eğilimlerini sinırlayan, yetersiz ve ilkesiz üyeleri meslekten dışlayan, rekabeti düzenleyen ve hizmet ideallerini korumayı amaçlayan mesleki ilkelerdir. Bu ilkeler; doğruluk, güvenirlilik, yeterlilik, mesleğe bağlılık ve yasalara uyma şeklinde özetlenebilir [3, 4].

Diğer mesleklerle karşılaştırıldığında toplum, mühendisleri günlük yaşamdaki birçok faaliyet ve olaydan direkt sorumlu tutmaktadır $[5,6]$. Dolayısıyla bizler için meslek etiği ilkelerinin algılanma ve uygulanma düzeyi son derece önem arz eden bir husus olarak karşımıza çıkmaktadır.

Dünyada mühendislik alanında var olan ilk etik kurallar Amerikan Elektrik Mühendisleri Enstitüsü (AIEE) tarafından 1912 yılında gerçekleştirilmiştir [7]. 1976 y1lında Illinois Teknoloji Enstitüsünde çeşitli mesleklerde yer alan etik değerler ve koyulmuş olan kurallarla ilgili çalışma yapmak üzere bir Etik Çalışma Merkezi (CSEP) kurulmuştur. Bugün CSEP kütüphanesinde yaklaşık 10 farklı ülkeden 21 farklı birlik tarafından oluşturulmuş 90 adet etik kuralı bulunmaktadır. Amerikan Ulusal Profesyonel Mühendisler Birliği (NSPE) tarafindan da temel mühendislik etik ilkeleri aşağıdaki gibi tanımlanmıştır [7]:

- Mühendisler, mesleki görevlerini yerine getirirken toplumun güvenliğini, sağlığını ve refahını en önde tutacaklardır.

- Mühendisler, sadece kendi uzmanlık alanlarındaki hizmetleri vermelidirler.

- Mühendisler, yalnızca objektif ve gerçek resmi raporlar yayınlayacaklardır.

- Mühendisler, mesleki konularda her işveren veya müşteri için güvenilir vekil olarak davranacaklar ve çıkar çatışmalarından kaçınacaklardır.

- Mühendisler, hizmetlerinin geçerliliği konusunda mesleki itibarlarını oluşturacak ve diğerleriyle haksız rekabete girmeyeceklerdir.

- Mühendisler; mesleki doğruluğunu, onurunu ve değerini yüceltmek ve geliştirmek için çalışacaklardır.
- Mühendisler, mesleki gelişmelerini kendi kariyerleriyle devam ettirecekler ve kendi kontrolleri altındaki mühendislerin mesleki açıdan gelişmeleri için olanaklar sağlayacaklardır.

Ülkemizde ise mühendislik etiği adı altında hazırlanmış özel resmi bir düzenleme olmamasına rağmen, 5176 sayılı Kamu Görevlileri Etik Kurulu Kurulması ve Bazı Kanunlarda Değişiklik Yapılması Hakkında Kanunun 3 ve 7. maddelerine dayanılarak 2005 yılında hazırlanmış olan ve belirli kamu daireleri ile bunların personelini kapsayan "Kamu Görevlileri Etik Davranış İlkeleri ile Başvuru Usul ve Esasları Hakkında Yönetmelik" çıkarılmıştır. Bu yönetmelikte belirtilen etik davranış ilkeleri ana başlıklar halinde sıralanmıştır [8]:

- Görevin yerine getirilmesinde kamu hizmeti bilinci,

- Halka hizmet bilinci,

- Hizmet standartlarına uyma,

- Amaç ve misyona bağlilık,

- Dürüstlük ve tarafsızlık,

- Saygınlık ve güven,

- Nezaket ve saygi,

- Yetkili makamlara bildirim,

- Çıkar çatışmasından kaçınma,

- Görev ve yetkilerin menfaat sağlamak amaciyla kullanılmaması,

- Hediye alma ve menfaat sağlama yasağı,

- Kamu malları ve kaynaklarının kullanımı,

- Savurganlıktan kaçınma,

- Bağlayıcı açıklamalar ve gerçek dışı beyan,

- Bilgi verme, saydamlık ve katılımcılık,

- Yöneticilerin hesap verme sorumluluğu,

- Eski kamu görevlileriyle ilişkiler,

- Mal bildiriminde bulunma.

Ülkemizde mühendislik etiği adına resmi bir düzenleme olmamasına rağmen mühendis odalarının kabul ettiği, NSPE etik ilkelerine paralel ilkeler mevcuttur. Ülkemizde ayrıca temel etik ilkelerden yararlanılarak "Mühendislik Yemini" adı altında aşağıdaki yemin oluşturulmuş ve günümüzde, ülkemizdeki birçok mühendislik fakültesi mezuniyet törenlerinde mezun olan mühendisler tarafindan okunmaktadır. 
Mühendislik Yemini [9]:

"Bana verilen mühendislik unvanını, sağladığı yetkilerin ve yüklediği sorumlulukların bilincinde olarak ülkenin ve tüm dünyanın yararı için tarafsız ve doğru davranmaya, meslek yaşamı boyunca doğaya ve insanlığa zarar vermemeye, bilgi ve becerilerimi sürekli geliştirerek mesleğin saygınlığını, etkinliğini ve toplumun yaşam kalitesini yükseltmeye özen göstereceğime ant içerim."

\section{MATERYAL ve METOT}

$\mathrm{Bu}$ çalışma, web tabanlı bir anketin analizine yöneliktir. Anketin ilk kısmında; etik algısı, herhangi bir eylemi etik açıdan değerlendirirken ve etik olduğuna karar verirken hangi uygun olan yaklaşımın dikkate alınması gerektiği, yapılacak bir işte etik olarak uygun görülmeyen bir durum karşısında sergilenen tutumun ne olduğu, Türkiye ‘ de inşaat sektöründe çalışan teknik elemanların bilerek veya bilmeyerek mesleki görevlerini yerine getirirken etik olmayan ne tip davranışlar sergiledikleri, etik olmayan davranış ve uygulama içindeki bir teknik elemana nasıl ve ne şekilde bir yaptırımın uygulanması gerektiği ve teknik elemanların etik dışı davranışlarda bulunmaması için olası çözüm önerileri sorgulanmıştır. Hazırlanan anket, meslek odaları vasıtasıyla Türkiye'nin çeşitli ilerinde kamu ve özel sektörde çalışan inşaat mühendislerine ulaştırılmıştır. Link, bir kişinin anketi birden fazla kez yanıtlamasını engellemek amaciyla her bilgisayarda yalnızca bir kez çalışacak şekilde programlanmıştır. Araştırmanın evreni Türkiye genelinde kamu ve özel sektörde çalışan inşaat mühendisleri olup, örnek uzayı ise 114 adet inşaat mühendisidir.

\section{ARASSTIRMA BULGULARININ DEĞERLENDİRILMESI}

Çalışmanın bulgular kısmı; ülkemiz kamu ve özel sektöründe çalışan inşaat mühendislerinin mesleki etik algısını anlamak, iş hayatlarında etik olmayan bir durum karşısında verdikleri tepkiyi ölçmek, inşaat sektöründe çalışan teknik elemanların bilerek veya bilmeyerek en çok hangi etik dışı davranışları sergilediklerini belirlemek, etik dişı davranışlarda bulunanlara nasıl ve ne şekilde bir yaptırım uygulanması gerektiğini tespit etmek ve etik dışı davranışlarda bulunulmaması için olası çözüm önerilerinin değerlendirilmesi ve yorumlanması üzerine kurgulanmıştır.

Çizelge 1. İnşaat mühendislerinin etik algısı

\begin{tabular}{|c|c|c|}
\hline \multirow{2}{*}{$\begin{array}{l}\text { Aşağıdaki etik ile } \begin{array}{r}\text { ilgili } \\
\text { düşüncelerden } \\
\text { onaylamaktasınız? }\end{array} \\
\text { hangisini } \\
\end{array}$} & \multicolumn{2}{|c|}{ Evet Hayır } \\
\hline & $\%$ & $\%$ \\
\hline $\begin{array}{l}\text { Etik, düşünsel düzeyde iyi veya } \\
\text { kötü yöndeki sınırsız özgürlüğü } \\
\text { temsil eder. } \\
\text { Etik olmayan düşünce yoktur, } \\
\text { etik olmayan davranış vardır. }\end{array}$ & 50,9 & 49,1 \\
\hline $\begin{array}{l}\text { Etik ne yapılabileceği hakkında } \\
\text { yargılara varmaz, eylemin ahlaki } \\
\text { olması için nasıl davranılması } \\
\text { gerektiği konusunda yardımcı } \\
\text { olur. }\end{array}$ & 86,8 & 13,2 \\
\hline $\begin{array}{l}\text { Etik düşünce, uygulamada ahlaki } \\
\text { açıdan yapılması gerekli bir } \\
\text { davranışı reddedebilir, hatta } \\
\text { ahlaka aykırı davranabilir. }\end{array}$ & 17,5 & 82,5 \\
\hline
\end{tabular}

Çizelge 1 incelendiğinde katılımcıların çoğunun $(\% 86,8)$ etiğin ne yapılabileceği hakkında yargılara varmadığı, eylemin ahlaki olması için nasıl davranılması gerektiği konusunda yardımcı olduğu konusunda hemfikir iken, en az konsensüs $(\% 17,5)$ etik düşüncenin, ahlaki açıdan yapılması gerekli bir davranışı reddedebileceği, hatta ahlaka aykırı davranabileceği görüşünde sağlanmıștır.

Çizelge 2 incelendiğinde, ankete katılan inşaat mühendislerinin \%58,8'inin bir eylemi etik açıdan değerlendirirken ahlaki yargı ve ahlaki davranış açısından içselleştirilmiş rasyonel ve tutarlı bir inceleme yaptığ 1 \% $\% 28,1$ 'inin yapılan/yapılacak eylemin yararlarını ve zararlarını analiz ettiğini, \%13,2'sinin ise durumların algılanış biçimleri üzerine odaklanarak ciddi bir araştırma yaptığı görülmektedir. 
Çizelge 2. İnşaat mühendislerinin bir eylemi etik açıdan değerlendirirken sergiledikleri yaklaşım

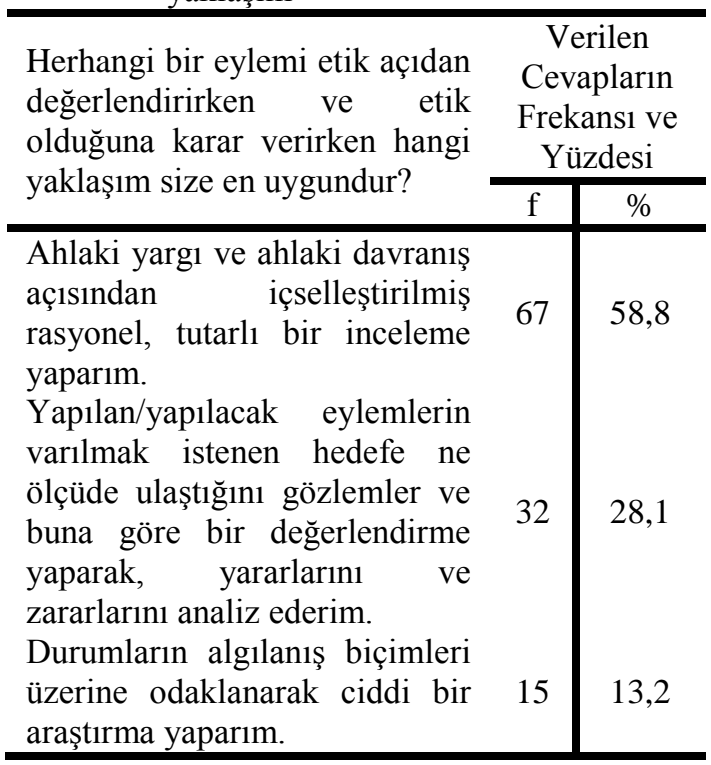

Çizelge 3. İnşaat mühendislerinin etik olarak görmedikleri bir iş karşısındaki tutumu

\begin{tabular}{lc|c}
\hline & \multicolumn{2}{c}{$\begin{array}{c}\text { Verilen } \\
\text { Yapacağınız bir işte etik olarak }\end{array}$} \\
$\begin{array}{l}\text { Cevapların } \\
\text { uygun görmediğiniz bir durum } \\
\text { karşısında tutumunuz ne olur? }\end{array}$ & $\begin{array}{c}\text { Frekansı ve } \\
\text { Yüzdesi }\end{array}$ \\
\cline { 2 - 3 } & $\mathrm{f}$ & $\%$ \\
\hline İși yapmamak & 32 & 28,1 \\
İşi sorgulamadan yapmak & 3 & 2,6 \\
İstifa etmek & 0 & 0,0 \\
Yöneticiyi ikna etmek & 79 & 69,3 \\
\hline
\end{tabular}

Çizelge 3 incelendiğinde ankete katılanların $\% 69,3$ 'ünün, etik olarak uygun görmedikleri bir iş ile karşılaştıklarında bu işi yapmak yerine yöneticilerini aksi yönde ikna etmeye çalışmayı tercih ettiği, \%28,1'inin karşılaş̧ıkları etik dışı işi yapmadığı, \%2,6'sının ise bu tür bir işi sorgusuz sualsiz yapmayı tercih ettikleri görülmektedir. Cizelge 4 incelendiğinde, katılımcıların $\% 37,7$ 'sinin etik olmayan davranışta bulunan bir teknik elemanın uyarılması gerektiği kanaatindeyken \%17,5' u ise kınanması gerektiğini düşünmektedir.

Çizelge 4. Etik dışı davranışta bulunan teknik elemanlara uygulanması gereken yaptırımlar

\begin{tabular}{|c|c|c|}
\hline \multirow{2}{*}{$\begin{array}{l}\text { Sizce etik olmayan davranış } \\
\text { ve uygulama içindeki bir } \\
\text { teknik elemana nasıl bir } \\
\text { yaptırım uygulanmalıdır? }\end{array}$} & \multicolumn{2}{|c|}{$\begin{array}{c}\text { Verilen } \\
\text { Cevapların } \\
\text { Frekansi ve } \\
\text { Yüzdesi }\end{array}$} \\
\hline & $\mathrm{f}$ & $\%$ \\
\hline İşten çıkarma & 18 & 15,8 \\
\hline Meslekten ihraç & 11 & 9,6 \\
\hline Kınama & 20 & 17,5 \\
\hline Uyar1 & 43 & 37,7 \\
\hline $\begin{array}{l}\text { Herhangi bir yaptırım } \\
\text { uygulanmamalı }\end{array}$ & 2 & 1,8 \\
\hline Diğer & 20 & 17,5 \\
\hline
\end{tabular}

Diğer seçeneğini seçen \%17,5' lik bir kesimin büyük çoğunluğu (\%60), etik dışı davrananların önce uyarılması gerektiğini, daha sonra ise işten çıkarma, meslekten ihraç vb. yaptırımlarla cezalandırılması taraftarı iken, $\% 15$ ' i ise etik dıșı davranışta bulunanlara eğitim verilmesinin gerekli olduğu yönünde görüş bildirmişlerdir. Çizelge 5 ağırlıklı ortalamalar göz önüne alınarak incelendiğinde, ankete katılan inşaat mühendislerinin mesleki görevlerini yerine getirirken bilerek veya bilmeyerek sergiledikleri etik olmayan davranış biçimi olarak ilk sıraya, bazı teknik elemanların işyerlerindeki diğer teknik elemanların ayağını kaydırmaya yönelik davranışlar sergilemelerini koymuşlardır. İkinci sırada ise, tasarım ve inşaat aşamaları esnasındaki

mesleki konularda, gerek iş kaygısı, gerekse donanımlı olmamaları, ya da mesleki kayg1 taşımaları ve bu nedenle, herhangi bilgi veya durumu işveren ya da müşterilerine bildirmemek yer almaktadır. En az yaşanan etik dışı davranış olarak ise, kendi işverenlerinin bilgisi olmaksızın, 
kendi düzenli işlerinin dışındaki mesleki konularda hizmet sunabilmek şeklinde görüş belirtmişlerdir.

Çizelge 5. Türkiye'de inşaat sektöründe çalışan teknik elemanların sergiledikleri etik dışı davranışlar

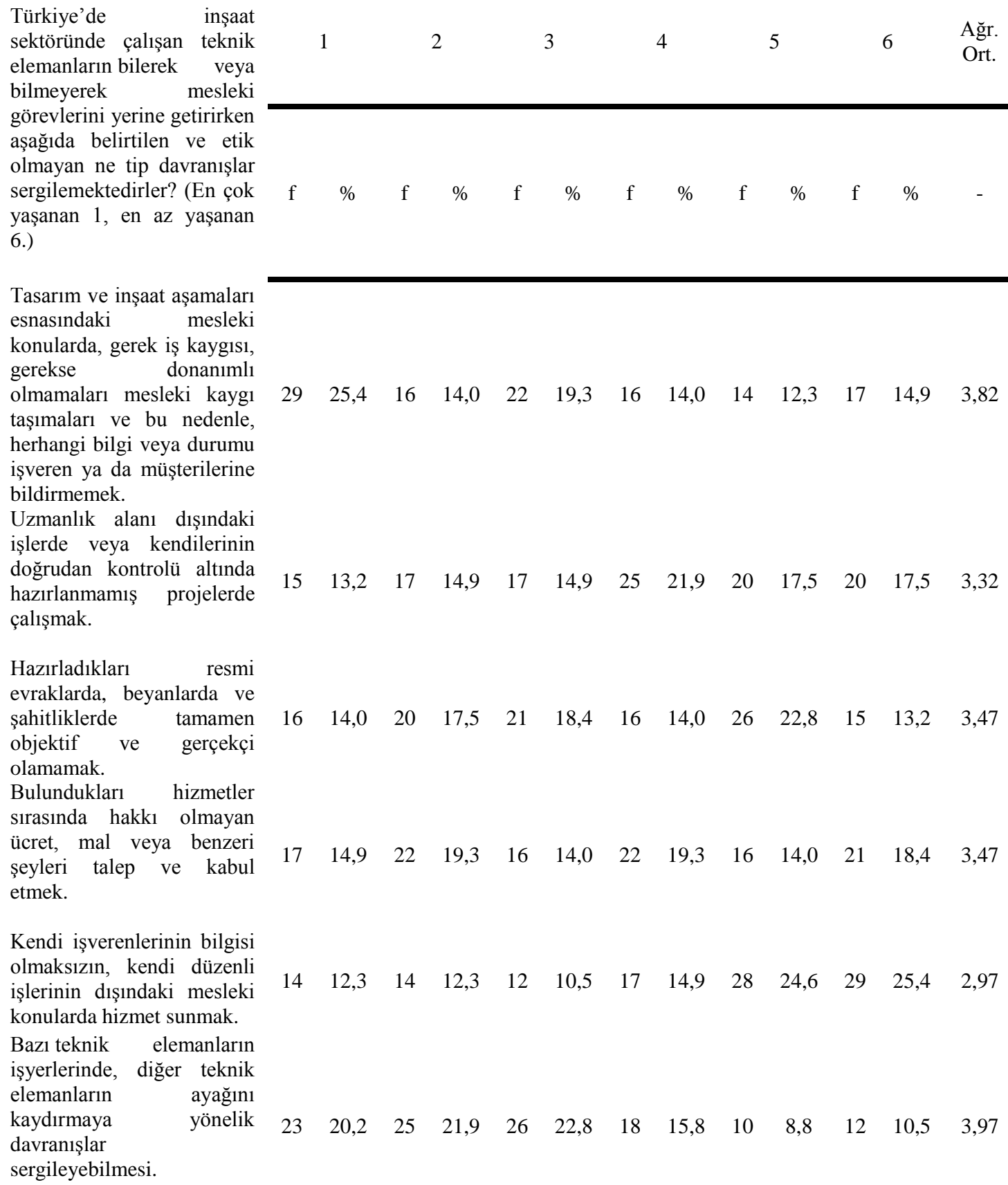

Kendi işverenlerinin bilgisi olmaksızın, kendi düzenli işlerinin dıșındaki mesleki konularda hizmet sunmak.

Bazı teknik elemanların işyerlerinde, diğer teknik elemanların ayağını kaydırmaya yönelik davranışlar $\begin{array}{lllllllllllll}29 & 25,4 & 16 & 14,0 & 22 & 19,3 & 16 & 14,0 & 14 & 12,3 & 17 & 14,9 & 3,82\end{array}$ $\begin{array}{lllllllllllll}15 & 13,2 & 17 & 14,9 & 17 & 14,9 & 25 & 21,9 & 20 & 17,5 & 20 & 17,5 & 3,32\end{array}$ sergileyebilmesi. 
Çizelge 6. Teknik elemanların etik dışı davranışlarda bulunmaması için atılması gereken adımlar

\begin{tabular}{|c|c|c|c|c|c|c|c|c|c|c|c|}
\hline \multirow{2}{*}{$\begin{array}{l}\text { Teknik elemanların etik dişı } \\
\text { davranışlarda bulunmaması için } \\
\text { çözüm önerileriniz neler olabilir, } \\
\text { önem derecesini belirtiniz? }\end{array}$} & \multicolumn{2}{|c|}{$\begin{array}{c}\text { Çok } \\
\text { Önemli }\end{array}$} & \multicolumn{2}{|c|}{ Önemli } & \multicolumn{2}{|c|}{ Kararsız } & \multicolumn{2}{|c|}{$\begin{array}{l}\text { Önemli } \\
\text { Değil }\end{array}$} & \multicolumn{2}{|c|}{$\begin{array}{l}\text { Hiç } \\
\text { Önemli } \\
\text { Değil }\end{array}$} & $\begin{array}{l}\text { Ağr. } \\
\text { Ort. }\end{array}$ \\
\hline & $\mathrm{f}$ & $\%$ & $\mathrm{f}$ & $\%$ & $\mathrm{f}$ & $\%$ & $\mathrm{f}$ & $\%$ & $\mathrm{f}$ & $\%$ & \\
\hline $\begin{array}{l}\text { Mesleki etik ile ilgili } \begin{array}{l}\text { yasal } \\
\text { mevzuatın bir an } \\
\text { oluşturulması }\end{array} \\
\text { önce }\end{array}$ & 48 & 42,1 & 44 & 38,6 & 10 & 8,8 & 7 & 6,1 & 5 & 4,4 & 4,08 \\
\hline $\begin{array}{l}\text { İşverenlerin ve çalışanların etik } \\
\text { konusunda duyarlılığ } 1 \text { artıracak } \\
\text { eğitimler verilmesi }\end{array}$ & 44 & 38,6 & 49 & 43,0 & 11 & 9,6 & 5 & 4,4 & 5 & 4,4 & 4,07 \\
\hline $\begin{array}{l}\text { İnşaat işlerinde bu doğrultuda } \\
\text { yapılacak } \\
\text { arttırılması }\end{array}$ & 47 & 41,2 & 39 & 34,2 & 10 & 8,8 & 13 & 11,4 & 5 & 4,4 & 3,96 \\
\hline $\begin{array}{l}\text { Meslek etik ilke ve kodlarının } \\
\text { tüm paydaşların önerileri } \\
\text { doğrultusunda oluşturulması }\end{array}$ & 38 & 33,3 & 43 & 37,7 & 20 & 17,5 & 10 & 8,8 & 3 & 2,6 & 3,90 \\
\hline
\end{tabular}

Çizelge 6, 5'li Likert ölçeğine göre değerlendirilmiş olup çok önemli seçeneğine 5 , hiç önemli değil seçeneğine 1 puan olacak şekilde seçenekler arasında puanlama yapılmış ve ağırlıklı ortalamalar çıkarılmıştır. Bu değerlendirmeye göre ankete katılan inşaat mühendisleri, teknik elemanların etik dışı davranışlarda bulunmaması için kendilerine sunulan çözüm önerilerinin hepsini önemli derecede değerlendirmişlerdir. Önem derecesinde mesleki etik ile ilgili yasal mevzuatın bir an önce oluşturulması 4,08 ağırlıklı ortalama ile ilk sırada değerlendirilirken, meslek etiği ilke ve kodlarının tüm paydaşların önerileri doğrultusunda oluşturulması 3,90 ağırlıklı ortalama ile son sırada yer almaktadır.

\section{SONUÇLAR ve ÖNERİLER}

Amacı, ülkemiz kamu ve özel sektöründe çalışan inşaat mühendislerinin mesleki etik algısını, iş hayatlarında etik olmayan bir durum karşısında verdikleri tepkiyi, inşaat sektöründe çalışan teknik elemanların bilerek veya bilmeyerek en çok hangi etik dışı davranışları sergilediğini, etik dışı davranışlarda bulunanlara nasıl ve ne şekilde bir yaptırım uygulanması gerektiğini ve etik dışı davranışlarda bulunulmaması için çözüm önerilerini saptamak olan bu çalışmada, konu ile ilgili Türkiye genelinde özel ve kamu sektöründe çalışan 114 inşaat mühendisinin görüşlerine başvurulmuştur. Elde edilen sonuçlar 1şığında, Türkiye'de kamu ve özel sektörde çalışan inşaat mühendislerinin; sadece kavram olarak etik algısına sahip oldukları, bir eylemi etik açıdan değerlendirirken genellikle ahlaki yargı ve ahlaki davranış açısından içselleştirilmiş rasyonel ve tutarlı bir inceleme yaptıkları, etik dışı davranış olarak daha çok meslektaşlarının ayağını kaydırmaya yönelik davranışlar sergiledikleri, etik olarak uygun görmedikleri bir iş ile karşılaştıklarında ise, çoğunlukla bu işi yapmak yerine yöneticilerini aksi yönde ikna etmeye çalıştıkları, etik olmayan davranışta bulunan bir teknik elemanın ise öncelikle uyarılması gerektiği görüşünde oldukları sonucuna varılmıştır. Çalışmada, ülkemizdeki teknik elemanların etik dışı davranışlarda bulunmamaları için atılması gereken adımlar ise aşağıdaki şekilde sıralanmıştır:

- Meslek etiği ilke ve kodları tüm paydaşların önerileri doğrultusunda oluşturulmalıdır.

- Mesleki etik ile ilgili yasal mevzuat bir an önce oluşturulmalıdır.

- İşverenlerin ve çalışanların mesleki etik konusundaki duyarlılığını artıracak eğitimler verilmelidir. 
- Sektör ve şirket bazında bu doğrultuda iç ve dış denetimler yapılmalıdır.

\section{KAYNAKLAR}

1. Gençoğlu, T.M., 2008. Mühendislikte Etik, TMMOB Elektrik Mühendisleri Odası Ankara Şubesi Haber Bülten, 5:26-31.

2. Ulutaş, A., Mühendislikte Etik, TMMOB Jeoloji Mühendisleri Odas1 Öğrenci Üye Kurultayı Bildiriler Kitabı, 165-168, İzmir.

3. M.E.B., 2006. Meslek Etiği, Meslekî Eğitim ve Öğretim Sisteminin Güçlendirilmesi Projesi, 64s, Ankara.

4. Farahani, F.M., Farahani, F.F., 2014. The Study on Professional Ethics Components Among Faculty Members in the Engineering, Procedia Social and Behavioral Science, 116:2085-2089.

5. Ooi, C.P., Tan, T.T.M., 2015. Effectiveness of Workshop to Improve Engineering Students' Awareness on Engineering Ethics, Procedia Social and Behavioral Science, 174:2343-2348.

6. Demirkol, M., Bilim ve Mühendislik Etiği, İmalat Mühendisliğine Giriş Ders Notları, Işık Üniversitesi, İstanbul.

7. Korhan, O., 2010. Profesyonel Mühendislik Etiği, Emo Bilim, 42-44.

8. Kamu Hizmetlerinin Sunumunda Uyulacak Usul ve Esaslara İlişkin Yönetmelik, http://www.etik.gov.tr/Mevzuat.aspx?id=3 (Erişim Tarihi 25.01.2016)

9. İnşaat Mühendisleri Odas1, http://www.imo.org.tr/imo_hakkinda/muhendis in_yemini.php\#.VyhVxmNeStk

(Erişim Tarihi 25.01.2016) 